\title{
Arte feminista no Brasil? Algumas vias para o debate
}

\author{
Elogio ao toque ou como falar de arte feminista à brasileira
}

BARROS, Roberta.

Rio de Janeiro: Relacionarte, 2016, 270p.

O livro da escritora-artista Roberta Barros é baseado na sua tese de doutorado realizada no Programa de Pós-Graduação em Artes Visuais da EBA/UFRJ, trabalho com o qual, no ano de 2014, recebeu o prêmio Gilberto Velho de teses. ${ }^{~}$ Através de uma escrita bastante autoral, Barros disserta sobre um tema ainda pouco explorado, ou quando não visto com estranhamento por pesquisadoras/es, teóricas/os, críticas/os, curadoras/es e historiadoras/ es da arte no país: a arte feminista.

Dentre as pesquisas realizadas no Brasil sobre arte feminista, seja a respeito da arte produzida por pessoas autodeclaradas feministas ou não, pode-se afirmar que, até o presente momento, este seja o trabalho que reúne mais informações e, ao mesmo tempo, aprofunda pontos nodais ainda pouco problematizados. O estudo, além do resgate crítico dos eventos e publicações estrangeiros, apresenta um levantamento inédito de artistas, obras e textos que tratam de arte feminista no Brasil apresentando-os em paralelo com as pautas dos movimentos feministas das chamadas primeira, segunda e terceira 'ondas'. ${ }^{2}$

Trata-se aqui não só de observar as produções das/os artistas feministas, mas também de como podemos teorizar sobre nossas/os artistas também à brasileira, buscando nossa própria linguagem, numa espécie de antropofagia da qual propõe Roberta Barros. O livro deixa explícito que o objetivo não é apenas falar de arte feminista brasileira, mas, retomando o título da publicação - como falar de arte feminista à brasileira - de, sobretudo, pensar

\section{(c) 6}

Esta obra tem licença Creative Commons.

1 BARROS, Roberta. "Pesquisadora reflete sobre a relação entre feminismo e artes visuais". O Globo, 20/03/ 2016 às 5:50 e atualizado às 10:25. Entrevista concedida a Josy Fischberg. Disponível em: https:// oglobo.globo.com/cultura/livros/pesquisadora-reflete-sobre-relacao-entre-feminismo-artes-visuais-18919094. Acesso em 26/09/2016.

2 No Brasil, as ondas ou 'tendências' (Céli Regina Pinto, 2003) do feminismo se caracterizam segundo as lutas e conquistas que marcaram cada momento histórico. Grosso modo, a primeira onda - do final do século XIX até as primeiras décadas do século XX - foi marcada pelas lutas pela igualdade na educação e pelo direito ao voto; a segunda onda - durante as décadas de sessenta a oitenta-discutiu a liberdade sexual e o direito ao corpo; enquanto que a terceira onda visa desconstruir os essencialismos e contradições presentes nas ondas anteriores para reivindicar novas identidades que reflitam sobre o sujeito do feminismo, associando-se por vezes ao termo "pós-feminismo" que pretende trazer questões para além da agenda tradicional. 
as possibilidades teórico-discursivas deste tema. Para promover uma perspectiva à brasileira, precisamos buscar uma linguagem a partir de nosso entendimento, da nossa leitura transpassada pela nossa história e pela nossa cultura.

O livro propõe discutir questões centrais e periféricas no desenvolvimento de uma possível antologia da arte feminista brasileira. Barros reflete sobre questões que muitas vezes haviam sido pouco exploradas em outras publicações ${ }^{3}$ e rompe muitos tabus acerca da arte feminista, contribuindo para enriquecer sua proposta de ir a fundo nesta aventura de pintar o retrato de uma arte feminista à brasileira.

Entre a introdução e a nota final, o texto divide-se em três grandes capítulos. No primeiro, "Comer e ser Comida", através do olhar do antropólogo Roberto DaMatta sobre a mulher brasileira, a autora faz uma releitura feminista do Manifesto Antropofágico, de Oswald de Andrade, inserindo uma perspectiva de gênero sobre a história da arte no Brasil de meados do século XX, passando de Anita Malfatti a Hélio Oiticica. Buscou desfazer o mito de que não houve discriminação contra as mulheres no campo artístico brasileiro, e que as artistas daqui não tiveram 'facilidades' em comparação às estrangeiras.

Nesse capítulo, além da atenção à reflexão sobre mestiçagem étnico-racial e cultural, Barros promove uma relação entre a ação de comer e a sexualidade ilustrada por meio de uma análise comparativa de duas instalações reveladoras de dois contextos muito diferentes: Arroz e feijão (1979), de Ana Maria Maiolino, e Dinners party (1974-79), de Judy Chicago. A partir disso, ela demonstra as particularidades do que ela chama de um feminismo à brasileira nascido em meio às questões políticas do Brasil dos anos sessenta e setenta. Para Barros (2016, p. 25), a leitura daquelas duas obras demonstra que Maiolino representa o nosso feminismo "escamoteado" e "doce" em contraponto ao feminismo "aguerrido" e ativista norte-americano.

O segundo capítulo, "Dieta das Imagens", apresenta questões específicas das artistas feministas e das mulheres que produzem arte feminista em contraponto à expectativa social de atuação passiva ou de mero objeto de representação. A autora faz um exame minucioso das reverberações do feminismo de segunda onda no Brasil destacando os aspectos históricosociais de ser 'mulher' entre as décadas de 1950 a 1990. Nesse sentido, sua série Costurar ${ }^{4}$ pretende problematizar a imagem de 'mulher' e de 'feminino' divulgada pela mídia de massas, como nas matérias publicadas em revistas 'femininas' costuradas pela artista.

Nessa seção, Barros dá continuidade ao diálogo entre as artistas brasileiras e estrangeiras que trabalham com arte conceitual através de materiais e/ou performances que se utilizam do corpo como meio para abordar temas subjetivos e ao mesmo tempo com viés políitico, como dor, prazer, beleza, sexualidade e identidade. Para isso, a autora explica interdisciplinarmente como se deu o trânsito de teorias entre a segunda e terceira vagas do feminismo, principalmente a partir da produção da filósofa Judith Butler, atentando para a contribuição da psicanálise freudiana e do pensamento de Michel Foucault para a construção do chamado feminismo pós-estruturalista.

\footnotetext{
${ }^{3}$ Existem outras pesquisas realizadas no Brasil que valem a pena ser destacadas, como a tese Mulheres artistas - Brasil, Mulheres artistas - Argentina, Crítica de arte feminista (2013) e a dissertação Figurações feministas na arte contemporânea: Márcia X, Fernanda Magalhães e Rosângela Rennó (2008), ambas realizadas no IFCH-Unicamp por Luana Saturnino Tvardovskas sob a orientação de Margareth Rago; e a dissertação Mulheres, arte e domesticidade: entre a arte feminista e o Dicionário do Lar (2012), de Silvia Amélia Nogueira de Souza, defendida na EBA-UFMG, sob a orientação de Mabe Machado Bethônico. Um artigo que inaugurou esta discussão no Brasil foi: Uma questão de política cultural: mulheres artistas, artesãs, designers e arte/educadoras (2010), escrito pela arte-educadora Ana Mae Barbosa.

${ }^{4}$ Segundo a autora, o interesse pelo tema foi em decorrência do trabalho Costurar (2005), no qual ela costurava com linha cirúrgica imagens de mulheres ilustradas em revistas "femininas" para discutir os padrões inalcançáveis de beleza vinculados pela grande mídia.
} 
Além de serem chamadas como essencialistas pelas teóricas feministas pósestruturalistas dos anos 1980, as artistas que apresentavam temáticas feministas sofreram também com os ataques da arte formalista que negava o corpo e a expressão narcísica da/o artista. Isso também pode ter sido um fator determinante para a negação a qualquer associação com o feminismo por parte das artistas brasileiras, sob pena de serem estigmatizadas e deixadas de fora do circuito artístico. Sobre isso, vale destacar que até mesmo as artistas que seguiam a cartilha acadêmica ou eram adeptas dos temas considerados femininos acabaram excluídas de muitas coleções de museus, como também da história da arte, conforme atesta a própria autora sobre a "desproporção numérica aguda" (BARROS, 2016, p. 13-14) entre homens e mulheres de relevo na arte brasileira.

No terceiro e último capítulo, "Elogio ao toque", Barros propõe uma discussão mais teórica, ao retomar os temas previamente citados com os vieses foucaultiano e psicanalítico para, junto aos conceitos de sexualidade e de abjeção ${ }^{5}$, analisar a correspondência de discursos na teoria e na arte feminista. Barros apresenta o trabalho de Márcia X, uma referência pessoal de seu repertório artístico e articula uma análise de sua própria produção afinada com o pensamento de Lucy Irigaray, Monique Wittig e Judith Butler.

A escritora-artista parte da reflexão sobre sua performance Dar de $s^{6}$ para estabelecer pontes com produções pioneiras da arte feminista no Brasil e no exterior por ela descritas e interpretadas à luz da teoria feminista. A autora encerra o capítulo dando continuidade à explicação de Dar de Si associando-a aos comportamentos esperados para as mulheres em relação à sua sexualidade, principalmente em torno da figura da mulher-mãe e do enfrentamento ao improvável reencontro com sua natureza desvinculada da maternidade "natural" e assexuada.

De acordo com Barros, a fuga das artistas brasileiras de temas relacionados ao feminismo, os quais pudessem enquadrar ou rotular seus trabalhos, resultou na ausência de qualquer teorização de viés feminista para a leitura daquelas obras, tornando-se um entrave para as pesquisas sobre esta perspectiva. Nesse sentido, e num gesto de compartilhar esta preocupação, no último parágrafo a autora parece convidar as/os leitoras/es a realizarem estudos sobre a produção artística feminista brasileira, apontando para a infinidade de nuances a respeito das questões de gênero que ainda estão para serem estudadas.

Barros destaca que, assim como o Brasil teve suas especificidades com relação aos feminismos de primeira e de segunda ondas ocorridos na Europa e nos Estados Unidos, as elaborações da arte feminista também assumiram outros contornos quando manifestas no contexto brasileiro. Do mesmo modo que as demandas dos movimentos de mulheres e do feminismo tiveram pouco espaço frente aos problemas "mais urgentes" de resistência ao regime ditadura civil-militar (1964-1985), a arte feminista teria ficado em segundo plano entre aquelas artistas que desejavam inserir-se no mercado e construir uma carreira no Brasil. A autora apresenta os contextos europeu e norte-americano e, sem se deter aos demais países da América Latina, passa para a realidade brasileira. Parece que daria um sentido maior de unidade se o texto tivesse abarcado as discussões específicas do feminismo pós-colonial latino-americano, pela perspectiva das artes, numa comparação com a arte feminista latino-americana.

\footnotetext{
${ }^{5} \mathrm{O}$ abjeto em arte contemporânea diz respeito ao uso se materiais perecíveis, excrementos e fluidos corporais, largamente utilizados como "estratégia de afronta feminista" (BARROS, 2016, p. 191).

6 Inspirada na temática de Mary Kelley, pioneira do feminismo na arte conceitual, na performance artística Dar de si (2011) Roberta Barros extraiu leite dos seios em copos e depois o distribuiu ao público presente, buscando, com isso, discutir o aprisionamento cultural da mulher ao seu corpo materno.
} 


\section{Referências}

BARROS, Roberta. Elogio ao toque ou como falar de arte feminista à brasileira. Rio de Janeiro: Ed. Relacionarte, 2016.

PINTO, Céli Regina. Uma história do feminismo no Brasil. São Paulo: Ed. Fund. Perseu Abramo, 2003.

[Recebida em 15/04/2017

e aprovada em 30/09/2017]

Rebecca Corrêa e Silva Universidade Federal de Santa Catarina, Florianópolis, SC, Brasil

Rebecca Corrêa e Silva (rebeccasilllva@yahoo.com.br) é doutoranda no Programa de Pós-Graduação Interdisciplinar em Ciências Humanas da Universidade Federal de Santa Catarina (UFSC), Mestra em Gestão Cultural pela Universidade do Algarve - UAlg/ Portugal (2013), e Licenciada em Artes Visuais pela Universidade Federal de Pelotas (2009). Possui experiência na área de Artes, com ênfase na História e Teoria da Arte e suas relações com Gênero.

4 Revista Estudos Feministas, Florianópolis, 26(1): e50086 